\title{
HISTORIA Y MEMORIA: DEBATES Y TENSIONES EN EL SIGLO XXI ${ }^{1}$
}

\section{Resumen/Abstract}

\author{
Romane Landaeta ${ }^{2}$
}

El texto analiza la relación entre historia y memoria desde diferentes horizontes de reflexión teórica. Examina los debates teóricos que ofrece la historia del tiempo presente, así como los desafíos metodológicos que propone. Explora las complejidades que comporta el estudio de la memoria histórica, los usos y tipologías. A su vez, indaga en el reverso de la memoria, esto es, el olvido. La reflexión se plantea desde América Latina en diálogo con Europa, considerando para ello los pasados difíciles, vinculados a las violencias cometidas por los Estados en uno y otro continente en el pasado siglo.

Palabras claves: memoria histórica, olvido, acontecimiento, recuerdo, violencia política.

\section{HISTORY AND MEMORY: DEBATES AND TENSIONS IN THE 21 ST CENTURY}

The text analyses the relationship between history and memory from different horizons of theoretical reflection. It examines the theoretical debates offered by the history of the present time as well as the methodological challenges it proposes. Explore the complexities involved in the study of historical memory, uses and typologies. In turn, it investigates the reverse of memory, that is, oblivion. The reflection arises from Latin America in dialogue with Europe, considering for it the difficult pasts, linked to the violence committed by the States in one and another continent in the past century.

Keywords: historical memory, oblivion, event, remembrance, political violence

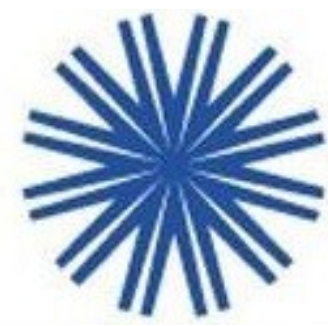

\section{Introducción}

El nuevo siglo fue recibido en latinoamericana en gran parte de sus países bajo gobiernos constitucionales, algunos con democracias más profundas, y teniendo la convicción de haber dejado atrás un pasado que había marcado en la memoria reciente las huellas de la violencia política. En efecto, a fines del siglo XX las consignas de Nunca Más, a propósito de las dictaduras militares que asolaron la región debido a la Doctrina de Seguridad Interior, que primó como política exterior de Estados Unidos en América Latina, dejó como consecuencia cientos de víctimas, debido a asesinatos, desaparecimientos, 1 Mis agradecimientos para Josefina Cuesta Bustillo por sus comentarios y sugerencias y a Juan Ignacio Radic Vega por la invitación para colaborar en este Dossier.

2 Boliviana, Universidad Simón Bolívar. E-mail: manelandaeta@gmail.com 
tortura sistemática y apresamientos, todos al margen de la ley. Fue durante los procesos de transición política a la democracia donde se crearon comisiones orientadas a la investigación de la verdad, debido a la demanda social de justicia, exigida por las víctimas y sus familiares, lo que impulsó a los gobiernos de la región a afrontar con diferentes medidas y énfasis las herencias de las dictaduras militares, sobre todo en materia de derechos humanos.

En ese contexto, el artículo pretende abordar las reflexiones y debates frente a los complejos pasados del presente latinoamericano, tomando como elementos centrales los debates teóricos y metodológicos referidos a la historia del tiempo presente, memoria y olvido. El interés de examinar estas cuestiones tiene relación con identificar las formas en que las sociedades latinoamericanas han afrontado las herencias de los pasados autoritarios de cara al siglo XXI.

\section{Historia del Tiempo Presente, un estado de la cuestión}

En diversas regiones del mundo las experiencias traumáticas que dejaron las violencias políticas producto de dictaduras militares y gobiernos autoritarios, que se advierten sobre todo a partir de la segunda mitad del siglo XX, dejaron un pasado cercano complejo, sobre todo por las devastadoras consecuencias en materia de derechos humanos y el desagarro que significó la narración de la experiencia de violencia infringida para las víctimas y sobrevivientes.

Los hechos ocurridos llevan a replantear la metodología con que nos acercamos a estos problemas. Es en medio de estas complejidades que desde nuestro oficio se observa un profundo debate orientado a tratar los temas vinculados a los pasados recientes. Si bien el Instituto de Historia del Tiempo Presente $(\text { IHTP })^{3}$, lleva más de tres décadas de investigación, todavía se observa cierta incomodidad al abordar estas proximidades temporales, más aun, si contienen hechos de violencia política, observando que "la corporación de los historiadores, con sus reglas, sus cánones y sus métodos de trabajo, permanecía fiel a las enseñanzas de los maestros del siglo anterior" (Bédarida 1998: 19). Por ello la creación en 1978 del IHTP marcó un precedente en la forma de hacer historia: "Se trataba, a la vez, de incitar a la investigación histórica francesa a enfrentarse a lo muy contemporáneo y de afirmar la legitimidad científica de este fragmento o rama del pasado, demostrando a ciertos miembros de la profesión, más o menos escépticos, que el reto era realmente hacer historia y no periodismo" (Bédarida 1998: 20).

3 El Centro Nacional de Investigación Científica fundó en Paris en 1978 el Instituto de Historia del Tiempo Presente. Véase http://www.ihtp.cnrs.fr/. 
En este sentido se interrogaba Julio Aróstegui, “¿cómo podría? y, en consecuencia, ¿cómo debería el historiador acercarse a las realidades sociales presentes?" (Aróstegui 1998: 31). Esta es una de las cuestiones que comporta mayor dificultad ya que ¿cómo definimos el presente, desde la óptica del tiempo histórico? Entre otros historiadores, François Bédarida insistía en la necesidad de precisar estos temas, puesto que “(...) en sentido estricto no se puede hacer historia del presente, porque basta con hablar de ello para que se esté ya en el pasado. Es obligado, pues, alargar este dato instantáneo del presente que se escurre bajo nuestra mirada a fin de darle sentido y contenido" (Bédarida 1998: 21). Bédarida propone una definición del presente como, "el lugar de la temporalidad extendida que contiene la memoria de las cosas pasadas y la expectativa de las cosas por venir: 'el presente del pasado es la memoria; el presente del presente es la visión; el presente del futuro es la expectativa"" (Bédarida 1998: 21). En esta línea el historiador alemán Reinhart Koselleck identifica la reflexión sobre el presente como: "el intercambio entre el espacio de experiencia y el horizonte de espera que se lleva a cabo en el horizonte vivo de una cultura. Dicho presente no puede reducirse a un punto en la línea del tiempo, a un mero corte entre un antes y un después. Sólo puede definirse de ese modo un instante cualquiera, no el presente vivo." (Ricoeur 1999: 22).

En consecuencia, el problema del movimiento pendular del presente no es en estricto rigor la demarcación que puede existir hacia atrás, sino que la dificultad está hacia adelante, ya que las fronteras son difusas, siendo más bien un terreno movedizo. Por esta razón Bédarida insiste en llamar al tiempo presente como "el tiempo de la experiencia vivida" (Bédarida 1998: 21). En ello concuerda también la historiadora Anne Pérotin-Dumon, al indicar que "es poner el acento en la relación de contemporaneidad que la proximidad del pasado introduce entre el historiador o la historiadora y su objeto: es 'historizar la experiencia propia', se escribe "la historia del mundo en que vivimos" (Pérotin-Dumon 2007: 17). Asimismo, otro de los nudos que se observan es cuando se analiza la noción de acontecimiento, y que para América Latina cobra tanto sentido, más aún si pensamos en los pasados cercanos. Como señala Michel Trebistch, "Feliz o trágico, colectivo o individual, público o privado, un acontecimiento es, pues, lo que se distingue de la trama normal de los trabajos y los días" (Trebitsch 1998: 30). Y es que el acontecimiento adquiere relevancia superando el enfoque de la escuela historicista de finales del siglo XIX, que concebía al hecho histórico como un dato, reduciendo el trabajo histórico a criticar los documentos y a darles un orden secuencial que identificaba la causa y el efecto. 
A partir de los años 1970-1980, la puesta de nuevo en cuestión de los grandes sistemas explicativos y de las modelizaciones duras ha favorecido, entre otros 'retornos', el 'retorno del acontecimiento', pero un acontecimiento de naturaleza distinta al de la historia 'acontecimental' descalificado por la larga duración braudelina, después de que unas primeras iniciativas manifestasen precisamente la tentativa de reconciliar estructuras y acontecimientos. (Trebitsch 1998: 32).

En este aspecto, es importante lo que señala Koselleck, "los acontecimientos no pueden ser más que narrados y las estructuras descritas" (Trebitsch: 1998; 32). Argumenta que la cronología natural constituye el 'horizonte de sentido' del acontecimiento: “Es preciso mínimamente un antes y un después para constituir la unidad de sentido que hace de cada cosa que sucede un acontecimiento" (Trebitsch 1998: 32). Considera que las estructuras son fenómenos anclados en la temporalidad que necesitan determinaciones funcionales, identificando en ellas discontinuidades, y donde el acontecimiento se puede entender como "una estructura diacrónica, con secuencias y escenarios susceptibles de ser tipologizados y comparados: no es la singularidad el carácter repetitivo eventual lo que caracteriza un acontecimiento, sino el valor y el espesor de sus enunciados estructurales posibles" (Trebitsch 1998: 33).

Otra de las consideraciones posibles, es la que elabora Paul Ricoeur, quién en su reflexión sobre el acontecimiento, expone que "para la hermenéutica, entre el tiempo cósmico y el tiempo íntimo de la experiencia se desprende un 'tercer tiempo', el tiempo narrado por el historiador, el único que fundamenta el acontecer histórico" (Trebitsch 1998: 32-33). Ubica en una situación de suma importancia el oficio de historiadoras e historiadores, destaca la validez del acontecimiento histórico, e integra la convergencia conceptual de diferentes escuelas históricas; en especial de la escuela positivista e historicista, la primera que consideraba al acontecimiento histórico como puramente descriptivo, y la segunda que coloca el acento en el sentido globalizante. Paul Ricoeur se refiere a "un acontecimiento sobre significativo que no existe en estado bruto, sino que es siempre el resultado de una narración, de un discurso, de una representación, de una construcción narrativa constitutiva de una identidad fundamentadora" (Trebitsch 1998: 33). Argumenta que desde esta óptica se desplazan las diferencias entre memoria e historia, ya que el eje articulador sería tanto la narración como los testigos e historiadores, que otorgan coherencia al acontecimiento. En este sentido Trebitsch enfatiza que la experiencia temporal en Ricoeur no existe en tanto que es contada, narrada: “(...) el acontecimiento es deconstruido y reconstruido por la operación histórica. Con él no es la psicología la que retorna sino el análisis de los personajes, de los roles, de los 'actuantes', no es la historia política la que regresa sino el 
análisis del poder, de la decisión, del conflicto, no regresa la singularidad, sino la introducción, por ejemplo, en torno a la noción de crisis, de la probabilidad, la complejidad" (Trebitsch 1998: 33). Además, señala que la contribución tanto de la semántica de la historia como de la hermenéutica, han reabierto a su juicio un acercamiento 'estructural' al acontecimiento, y también 'una historia social de los acontecimientos históricos'.

De acuerdo a Trebitsch esta situación se produce al manejar el desplazamiento desde las estructuras o del relato al análisis de la acción, puesto que encuentra "el refuerzo de la sociología de la acción, que propone una aproximación constructivista según la cual el acontecimiento aparece como producto de un juego de interacciones entre una pluralidad de actores y agentes" (Trebitsch 1998: 33). Siguiendo este argumento las/os historiadoras/es se enfrentarían a dos cuestiones; De un lado, aquello que coloca el énfasis en la acción cuestionando las relaciones entre pasado, presente y futuro. Trebistch señala que pertinente considerar la propuesta de Bernard Lepetit, quien introduce un modelo temporal en que el presente de la acción es el tiempo de la historia, y donde el rol del historiador es analizar el proceso histórico como un presente en deslizamiento. De otro, se encuentra la idea desarrollada por Carlo Ginzburg y Georges Duby “el acontecimiento no es conocido más que por sus huellas" (Trebitsch 1998: 34). Dicho de otra forma, esa es la propuesta también de Koselleck cuando se refiere al espacio de experiencia, donde la función del/a historiador/a sería como ha escrito Pierre Nora, "analizar no los acontecimientos mismos sino su construcción en el tiempo, no el pasado sino su reutilización" (Trebitsch 1998: 34).

Estas cuestiones cobran vital importancia a propósito de las fechas 'in-felices' y las conmemoraciones que cada año se realizan en diversas regiones del mundo, y donde América Latina no es la excepción. En ellas es posible apreciar una preocupación social que se advierte tanto por la cercanía de los hechos como por la narración de memoria que las sociedades realizan. En ambas resulta esclarecedor incluir en el análisis el campo de análisis de lo generacional ya que existen pasados que exceden el propio acontecimiento -y no por casualidad- se inscriben en narraciones y pasados que de alguna manera se tornan emblemáticos. "El presente histórico está constituido por aquellas generaciones de se solapan sucesivamente generando una cadena de transmisión de acontecimientos que son reconocidos como 'su' pasado aun cuando no todos los hayan experimentado directamente" (Mudrovcic: 1998-2000). 
Sin duda una de las características de la Historia del Tiempo Presente, es que es una "historia viva no historia reciente, ni inmediata, por mucho que tenga estas características o connotaciones. Por mucho que se acerca a nuestro propio tiempo" (Bédarida: 1998:34). En consecuencia, el estudio de los pasados recientes recibe diversas formas de enunciación, lo que da cuenta de que aquello que se observa, analiza y preocupa tiene que ver con ese tiempo del que somos coetáneos, identificándolo como sinónimo de: "Tiempo de lo contingente, de lo incierto, del cambio de época, de la ruptura histórica; pero también es tiempo de la perplejidad y del asombro. Esta dimensión temporal es pensada por la mayoría de los historiadores con parámetros móviles a la hora de delimitar una historia del presente y se produce en la simultaneidad entre historia vivida e historia contada" (Iuorno: 2010; 40) ${ }^{4}$.

Al parecer esto es lo que genera mayor preocupación al momento de historizar los pasados recientes, ya que, si bien aprovecha el interés de estudio que suscita el siglo XX sobre todo a partir de la segunda mitad, quienes investigan estos temas enfatizan que ésta no comienza en 1945, sino que tiene un acento más bien dinámico. Señalan la necesidad de considerar las cuestiones referidas a la noción de tiempo histórico, y la importancia de la relación pasado-presente. En definitiva, la Historia del Tiempo Presente tiene una connotación más profunda en cuanto a su campo investigativo, esto es porque trata 'nuestro tiempo', como lo denomina Aróstegui, insistiendo en que es "un intento de historiar la experiencia propia, como lo fue la historia contemporánea hace algo más de siglo y medio. [...] El tiempo presente obliga a inevitables reacomodaciones y ampliaciones del también tradicional oficio del historiador. Es decir, tiene claras implicaciones metodológicas" (Bédarida 1998: 36).

La historiadora Graciela Iuorno, plantea que tanto la renovación teórica y metodológica de la disciplina, luego de la anunciada crisis de paradigmas, se puede rastrear en los congresos académicos de Historia a Debate, ya que, según su apreciación, “(...) estos encuentros posibilitaron la cristalización de un movimiento académico en red que tuvo su origen en 1993. Una década después, en el 2003, el referente y coordinador de la red Historia a Debate HaD -el historiador gallego Carlos Barros- acuña el concepto de Historia Inmediata, a partir de los aportes realizados a la red por el historiador ecuatoriano Juan Paz y Miño" (Iuorno 2010: 41). Agrega que la elección del nombre Historia a Debate HaD, se debe a que originalmente lo que se pretendía, era examinar desde la propia academia y en forma colectiva, lo que

4 La historiadora agrega que "el primer Congreso Internacional de Historiografía Historia a Debate celebrado en Santiago de Compostela (Galicia, España) dio el puntapié a una serie de encuentros entre profesionales de la historia que desafiaron a la historia profesional, a sus teorías, métodos y prácticas" (Iuorno 2010: 41). 
"le sucedía inmediatamente, coetáneamente a los historiadores que intercambiaban sus pareceres". Ya en el 2004, en el III Congreso Internacional de Historia a Debate "lo inmediato -la nueva especialidadocupó por primera vez un lugar importante en las discusiones, con enriquecedoras aportaciones historiográficas sobre tema" (Iuorno 2010: 41). Lo que expone Iuorno da cuenta de las formas de entender nuestro presente, donde la cultura es un elemento de análisis clave. "el estudio de la historia presente implica considerar el factor de cambio cultural y político, habida cuenta que es la historia de la cultura de nuestro tiempo" (Iuorno 2010: 42).

Siguiendo esta argumentación y vinculado a la metodología, otro problema tiene relación con "la complejidad de evaluar y discriminar cuáles son los hechos verdaderamente históricos cuando nosotros formamos parte de ese mismo proceso, y más aún, cuando los efectos de esos hechos aún son imperceptibles por ser procesos inacabados" (Iuorno 2010: 42). De suma importancia es lo que se refiere a las fuentes y archivos. Al acercarnos a las problemáticas y debates en torno a la Historia del Tiempo Presente, coincidimos en que una de las principales objeciones después de la "noción de 'distanciamiento' (recul), que parecía como el signo y garantía indispensable de la objetividad" (Bédarida 1998: 23), según expone el historiador François Bédarida, es el relacionado con las fuentes: "El problema de la accesibilidad a los documentos es esencial. Como es sabido, la tendencia general hoy en la mayor parte de los países es hacia el recorte de los plazos de apertura de los fondos recientes de archivos públicos" (Bédarida 1998: 24).

Estas problemáticas nos llevan a un desafío mayor, por cuanto asistimos a una abundancia de fuentes. Sin duda, éste es un importante tema, que toca directamente a aquellos países que luego de tener regímenes dictatoriales, se ven enfrentados al debate sobre la apertura de los archivos. En este aspecto, la región de América Latina es muy importante, ya que a propósito de las llamadas comisiones de verdad las organizaciones no gubernamentales de derechos humanos, generaron gran cantidad de documentación cuya información sobre sus pasados represivos ha sido de gran relevancia para el juzgamiento de casos de violación de derechos humanos. Las experiencias de "Argentina (1984) y Chile (1990) establecieron oficialmente comisiones que emitieron informes sobre la represión. En Bolivia (1982-1983), Uruguay (1985) y Paraguay (1992) la tarea recayó en comisiones parlamentarias" (Barahona 2002: 32). 
Las reflexiones que planteamos en este texto, tienen una problemática fundamental, y es que la historia del tiempo presente debe analizar e interpretar un tiempo del cual no conoce ni el resultado concreto ni el final (Aróstegui:1998). Es desde estas interrogantes donde instalamos nuestras preocupaciones mayores, por ello, la necesidad de indagar en los debates asociados a la Historia del Tiempo Presente, prestando especial atención a las tensiones sobre cómo historizar aquellos pasados recientes que tienen como característica la violencia de estado. En esta perspectiva coincidimos en que "La historización del presente equivale, de otra parte, a una historización del desarrollo. (...) [Que] significa un abandono de la idea de que los procesos en curso no pueden ser historiados de acuerdo con la vieja convención de que sólo aquellas realidades sociales de las que existe una perspectiva temporal que permite captarlas en sus detalles y consecuencias finales pueden ser objetos de la Historia” (Aróstegui: 1998; 42).

En este aspecto es interesante reflexionar cómo las sociedades latinoamericanas en general y chilena en particular han elaborado narraciones de memoria histórica sobre esos pasados recientes durante las transiciones políticas a la democracia, observando el posicionamiento que la comunidad civil adquiere frente a estos asuntos (De Mussy y Yavar 2008; Figueroa y Vicuña 2008). Estas consideraciones tienen como telón de fondo el hacer frente a pasados que encuentran sus puntos nodales, como denomina Julio Aróstegui a las herencias dejadas por las dictaduras, referidos a los legados dictatoriales que se observan en los ámbitos políticos, económicos, sociales y culturales vinculados a las violaciones de derechos humanos y que constituyen temas pendientes en la región. Sin duda hacerse cargo de pasados que tienen las características señaladas no es una tarea fácil, sin embargo, "por mucho que el pasado no determine totalmente el presente, sin aquel, este permanece ininteligible" (Bloch 2002: 150-151), de ahí la importancia de realizar un trabajo de memoria. Como expone Graciela Iuorno "la historia controvertida y de controversias actuales se asienta en una historia plural con conciencia de que existen diversos relatos posibles y plausibles de las mismas acciones y los mismos acontecimientos" (Iuorno 2010: 43).

Precisamente, son estas problemáticas las que plantean retos a la historia, incorporando nuevas metodologías de trabajo impulsando un continuo diálogo con otros campos del conocimiento en un análisis interdisciplinario que amplía el conocimiento de estos complejos pasados. “(...) la historia de lo 'presente' es una historia en buena parte distinta de las ya conocidas, pero también es claro que es 'historia' y no otra cosa, aunque sus relaciones con otras investigaciones sociales deban ser más estrechas todavía que en otros sectores historiográficos. Hacer del presente una historia plena, historizar 
el presente, requiere repensar la historiografía con rigor, lejos de convencionalismos" (Aróstegui 1998: $41)$.

Es importante que desde nuestro oficio nos hagamos cargos del estudio de problemáticas referidos al pasado cercano, y que dejamos a otros especialistas. Si bien existen riesgos es una tarea que deben realizar también los historiados, siguiendo a Eric Hobsbawm se puede argumentar desde categorías históricas, aunque se trate de procesos que están abiertos, lo que no quiere decir que no se pueda analizar el presente, por ejemplo, reconociendo el alcance de determinados acontecimientos que pueden llegar a ser claves desde el análisis histórico (Hobsbawm 1998: 230). En este aspecto, Gabriel Salazar insta a los nuevos historiadores a preocuparse de su tiempo, subrayando que: "La mayoría de los historiadores tradicionalistas desconocen, de hecho, el rango histórico del presente, al punto de que niegan la calidad de 'historiador' a los investigadores que se aventuran en él, a los que llaman, algo despectivamente, 'sociólogos"” (Salazar: 2007;104). Asimismo, Josefina Cuesta, invita a ampliar el campo de estudio: "El impacto de los medios de comunicación en la sociedad de masas de esta segunda mitad de siglo XX y la ampliación de la Historia hasta nuestros días ha llevado a periodistas e historiadores a confluir sobre un mismo campo de trabajo: el tiempo en el que viven. Un terreno propio y habitual para el profesional de las comunicaciones y, hasta hace poco, menos transitado por el especialista de la Historia" (Cuesta 1998: 131).

Estas preocupaciones desde y hacia nuestro quehacer disciplinario traspasan las geografías, observando las similitudes y diferencias que se pueden advertir al analizar sociedades que han tenido dictaduras militares, como señala Alexandra Barahona, “(...) una de las cuestiones políticas y éticas más importantes con que se enfrentan las sociedades durante la transición de un gobierno autoritario o totalitario a otro democrático es cómo hacer frente al legado de un pasado represivo. Éste es a menudo el problema con un mayor potencial para desestabilizar el proceso de transición" (Barahona: 2002; 29). En algunos casos, la necesidad de consensos y acuerdos de la sociedad en su conjunto presenta grandes paradojas. En el caso de Chile, el golpe de Estado, si bien tuvo objetivos definidos desde el principio, no es menos cierto que éstos se fueron complejizando en el transcurso de los años que duró la dictadura militar (1973-1990). Para llevar a cabo sus acciones requirió la instalación de instrumentos simbólicos y materiales, que permitieron concretar las acciones de impunidad que el propio estado amparó. Temas que están vinculados a sociedades que tienen un pasado traumático, han sido abordados con diferentes énfasis desde la filosofía por Hannah Arendt respecto a las 'herramientas' necesarias para ejecutar la 
violencia (Arendt: 1969). Y con otros énfasis Michel De Certeau, cuyas reflexiones implican aquello que es posible de 'nombrar' (De Certeau: 1999). Desde la sociología con las investigaciones de Elizabeth Jelin, y sus reflexiones sobre 'los trabajos de memoria, fechas in-felices, las marcas y emprendedores de memoria' (Jelin 2002; Jelin, Da Silva 2002; Jelin, Langland 2003; Jelin y Longoni 2005), que sumados a la investigación histórica como la de Pierre Nora, que es fundamental para la comprensión de los lugares de memoria, entendiéndolos no sólo como aquello tangible, sino como un repositorio de lo inmaterial y simbólico (Nora 1992: 19). Son elementos claves que otorgan un panorama de reflexión teóricometodológico que identifica la matriz conceptual desde la que es posible desplazar el análisis respecto a este tipo de pasados.

\section{Relaciones entre memoria y olvido}

Las formas del olvido

Es posible advertir una mayor profusión de investigaciones vinculadas al estudio de la memoria, puesto que es en el pasado siglo donde alcanza mayor visibilidad, debido a la impronta de las revoluciones y guerras. Siglo definido como corto y vertiginoso (Hobsbawn 1994), cuya característica fundamental es la catástrofe humana, representada por la violencia. De ahí que el concepto de memoria, tenga una mayor asociación con las situaciones traumáticas, ya que la impronta vivida ha sido mayoritariamente de guerras, genocidios, dictaduras, destrucción masiva del medioambiente, etc., y no es que antes no haya ocurrido (Todorov2005 28-29), sino que al examinar la historia del tiempo presente, debemos considerar que cualquier argumentación "a favor o en contra de su utilidad para la historiografía ha de tener no sólo la memoria traumática, sino también la memoria y la historiografía normativa" (Spiegel 2002: 56), ya que no asistimos a una ruptura con el pasado, sino una aceleración de los procesos históricos. Es en esta línea que seguimos a Elizabeth Jelin, quien expone que trabajar sobre la memoria no sería una inquietud aislada de un contexto político y cultural específico, sino más bien, que aún cuando intentemos reflexiones de carácter general, tendemos a hacerlo desde un lugar particular, en nuestro caso, de "la preocupación por las huellas de las dictaduras que gobernaron en el Cono Sur de América Latina entre los años sesenta y la década de los ochenta, y lo elaborado en los procesos postdictatoriales en los años noventa" (Jelin 2002: 4).

Es evidente que la memoria y los recuerdos construyen el pasado, adquiriendo la forma de segmentos o capas que se depositan en nuestro imaginario tornándose dinámicos, puesto que no recordamos de la 
misma manera, de ahí tal vez que aquello que retenemos de las experiencias vividas y narradas tiendan a variar, porque se tiñen de las prácticas acuñadas a lo largo de nuestra vida, re-significando episodios que antes posiblemente no tenían mayor trascendencia y, por el contrario, silenciando otros. Esta representación adquiere mayor connotación con el acto de habla, puesto que es "en el lenguaje, el destino de todos los términos que realmente tienen vida" (Bloch: 1996; 53). Y, si quisiéramos darles consistencia a estos enunciados, baste sólo indicar a los sobrevivientes de los campos de concentración en Europa y las víctimas de tortura y prisión política, para los casos de América Latina. Si como hemos enunciado la tragedia se ha hecho evidente en el pasado siglo, sobre todo por la proximidad del relato y la impronta de su narrativa, es en este escenario, un paisaje de la historia, parafraseando a John Lewis Gaddis (Lewis 2004), donde la memoria como objeto de la historia y por tanto fuente, se ha materializado por excelencia. De allí que nos interese analizar cómo ha sido leída, examinando la significación que adquiere para la comprensión de las proximidades históricas.

Por otra parte, es importante considerar que el olvido es el reverso indiscutible de la memoria. Historiográficamente ha sido abordado de forma tangencial, sobre todo a través del tratamiento de los archivos cuando se les ha interrogado con nuevas preguntas que, si bien dan cuenta de la inclusión de una mayor gama de categorías de análisis, permiten a la vez diagnosticar las ausencias, vacíos y huecos existentes sobre los pasados. Si bien existen diferentes formas de olvidos, ponemos el acento en los olvidos colectivos, que está compuesto de olvidos individuales. Si bien se ha investigado ampliamente este tema, es importante al menos mencionar el trabajo de Paul Ricoeur, quien desarrolla un importante análisis de los tipos de olvido en su libro La memoria, la historia y el olvido (Ricoeur 2003).

Entre las investigaciones -ya clásicas- que instalaron sospechas frente a aquellas fisuras u omisiones que presentaba la historiografía clásica, destacamos el trabajo de Arlette Farge. Sus publicaciones abordan una temporalidad que, si bien se aparta de nuestras preocupaciones, esto es, la sociedad francesa del siglo XVIII, logra situar la contemporaneidad de los hechos a través de ciertas tensiones que dan cuenta de la dinámica histórica. Farge identifica las identidades de los márgenes, visibilizando en los archivos judiciales a las mujeres en los espacios públicos (Farge 2008: 2010). Desde otras áreas del conocimiento, se han desarrollado importantes reflexiones vinculadas al olvido, diagnosticando sus matices y resistencias, las que van desde aquellos que se instalan de forma institucional, y que considera dentro de sus espacios de acción sólo aquellos vinculados a la polis, cuyas categorías se encuentren 
ligadas a la conformación del Estado-Nación, hasta la idea de comunidades imaginadas de Benedict Anderson (Anderson 2006). Precisamente existe la construcción de una memoria oficial, en que se evidencian olvidos, silencios y huecos institucionalizados en pos de una 'memoria patria' como lo denominaba Steve Stern (Stern: 2000).

Entre los valiosos estudios que abordan estas problemáticas se sitúan aquellos que prestan atención -a propósito de las catástrofes humanas cometidas sobre todo en el siglo XX- a las temáticas vinculadas a las violencias de estado, siendo el caso más emblemático el Holocausto judío. Considerando estas premisas, podemos indagar en algunas reflexiones que consideramos fundamentales para analizar ese 'reverso' de la memoria, y que constituye una parte fundamental la reflexión histórica, puesto que tras las preguntas sobre qué recordamos y cómo recordamos, están las interrogantes sobre qué olvidamos, cómo olvidamos y por qué olvidamos, y más aún, de qué deberíamos acordarnos y qué o quiénes pueden autorizar a olvidar. "Estrictamente, los pueblos y grupos sólo pueden olvidar el presente, no el pasado. En otros términos, los individuos que componen el grupo pueden olvidar acontecimientos que se produjeron durante su propia existencia; no podrían olvidar un pasado que ha sido anterior a ellos (...) un pueblo jamás puede 'olvidar' lo que antes no recibió” (Yerushalmi 1998).

Cuando se dice que un pueblo 'recuerda', en el fondo lo que se está planteando es que un tipo de pasado fue transmitido de manera activa a las generaciones contemporáneas, a través de lo que Yosef $H$. Yerushalmi ha denominado 'canales y receptáculos de la memoria' y que Pierre Nora identifica como 'los lugares de memoria', que es resignificado otorgándole un sentido propio. Quienes realizan este trabajo de memoria, Elizabeth Jelin los denomina 'emprendedores de memoria'. "Lo que llamamos olvido en el sentido colectivo aparece cuando ciertos grupos humanos no logran -voluntaria o pasivamente, por rechazo, indiferencia, indolencia, o bien a causa de una catástrofe histórica que interrumpió el curso de los días y las cosas- transmitir a la posteridad lo que aprendieron del pasado" (Yerushalmi1998: 18). Yerushalmi señala que un pueblo 'olvida' cuando la generación poseedora del pasado no lo transmite a la siguiente, o cuando ésta rechaza lo que recibió o cesa de transmitirlo. En consecuencia: "La experiencia humana incorpora vivencias propias, pero también las de otros que le han sido transmitidas. El pasado, entonces, puede condensarse o expandirse, según cómo esas experiencias pasadas sean incorporadas" (Jelin 2002: 13). 
Esta es una cuestión de una gran complejidad, porque de lo que se trata es de indagar en aquellas grietas, fracturas y huellas dejadas por la memoria. Elizabeth Jelin observa tres ejes de análisis, el primero el que se refiere a quién es el que rememora y olvida. El segundo a los contenidos, es decir, a qué se recuerda y qué se olvida. Y un tercer eje referido al cómo y cuándo se recuerda y olvida. En este aspecto Jelin advierte que esta última pregunta, surge debido a la ansiedad y angustia que genera la posibilidad del olvido. Señala que, tanto en el plano individual como social, las preocupaciones frente al olvido son similares. Subraya que, en el mundo occidental contemporáneo, el olvido es temido, ya que su presencia amenaza la identidad. Si bien tanto las capacidades de recordar y olvidar son singulares, no es menos cierto que no ocurren en individuos aislados, sino insertos en redes de relaciones sociales, en grupos, instituciones y culturas.

El olvido adquiere mayor relevancia cuando trata de aquello que genera rupturas frente a la vida cotidiana, o lo que algunos han llamado 'memoria habitual', generando las 'memorias narrativas'. Puesto que lo de que se trata no es mirar la memoria y el olvido desde perspectivas puramente cuantitativas, es decir, cuánto y qué se recuerda o se olvida, sino de comprender los cómo y cuándo, relacionándolos con elementos individuales de quién recuerda como con aquellos que son parte de una sociedad y que representan un tiempo histórico determinado, y que en palabras de Ricoeur corresponde a "la memoria como presente del pasado" (Ricoeur: 1999; 16). En el caso latinoamericano, corresponden a acontecimientos traumáticos los que conllevan grietas en la capacidad narrativa, generando huecos en la memoria, que corresponden a aquello inasequible que impide dar un sentido al acontecimiento pasado, aquello que imposibilita incorporarlo narrativamente, pero que a su vez coexiste con "su presencia persistente y su manifestación en síntomas, lo que indica la presencia de lo traumático. En este nivel, el olvido no es ausencia o vacío. Es la presencia de esa ausencia, la representación de algo que estaba y ya no está, borrada, silenciada o negada" (Ricoeur 1999: 28). En este tipo de narraciones de memoria, es posible encontrar las "heridas de la memoria, más que las memorias heridas" (Ricoeur 1999: 28).

Paul Ricoeur identifica dos niveles respecto al olvido. "En el nivel más profundo, éste se refiere a la memoria como inscripción, retención o conservación del recuerdo. En el nivel manifiesto, se refiere a la memoria como función de la evocación o de la rememoración" (Ricoeur: 1999; 53). El primer olvido, profundo e inexorable, se podría llamar también 'definitivo', y que "responde a la borradura de hechos y procesos del pasado, producidos en el propio devenir histórico". En este aspecto Elizabeth Jelin, indica 
que existen aquellos pasados que parecían olvidados de forma definitiva, pero que emergen cobrando vigencia debido a cambios en los marcos culturales y sociales que impulsan a revisar y dar nuevo sentido a huellas y restos, a los que no se les había dado significado durante décadas o siglos. "Las borraduras y olvidos pueden también ser producto de una voluntad o política de olvido y silencio por parte de actores que elaboran estrategias para ocultar y destruir pruebas y rastros, impidiendo así recuperaciones de memorias en el futuro -recordemos la célebre frase de Himmler en el juicio de Núremberg, cuando declaró que la 'solución final' fue una "página gloriosa de nuestra historia, que no ha sido jamás escrita, y que jamás lo será.” En casos así, hay un acto político voluntario de destrucción de pruebas y huellas, con el fin de promover olvidos selectivos a partir de la eliminación de pruebas documentales" (Jelin 2002: 29).

Este es un tema de gran alcance ya que toda política de conservación y de memoria, al seleccionar huellas para preservar, conservar o rememorar, tiene implícita una voluntad de olvido. Varios son los autores que nos recuerdan la responsabilidad de los historiadores e investigadores, cuando eligen qué contar, qué representar o qué escribir en un relato. De lo anterior, podemos deducir que lo que efectivamente deja el pasado son 'huellas' ya sea simbólicas, materiales, psíquicas, todas las que necesitan ser evocadas y ubicadas en un marco que les otorgue sentido.

El segundo tipo de olvido que señala Ricoeur, es aquel "que no consiste en la pérdida de las huellas o en la destrucción o disolución de los restos del pasado, sino en la aparición de impedimentos para acceder a nuestros recuerdos" (Ricoeur: 1999; 105). El problema que subyace no es la falta de huellas sobre ese pasado, sino más bien, los dispositivos de represión instalados desde diversos escenarios que evitan llegar a ellas, impidiendo la elaboración de esas memorias. Lo contrario sería lo que Andreas Huyssen denomina como "obsesión de la memoria".

Ricoeur identifica un tercer tipo de olvido, que denomina 'evasivo', y que corresponde al que se esquiva para evitar el sufrimiento en un intento de no recordar aquello que puede herir. Este "se da especialmente en períodos históricos posteriores a grandes catástrofes sociales, masacres y genocidios, que generan entre quienes han sufrido la voluntad de no querer saber, de evadirse de los recuerdos para poder seguir viviendo" (Semprún 1997). También se puede transformar en un olvido 'activo', situación que tiene lugar sobre todo en "el plano de la historia y de las grandes catástrofes históricas, en épocas de grandes pérdidas o de grandes masacres, como sucedió en Europa, por ejemplo, en tiempos de la Shoah" 
(Ricoeur 1999: 105). Ahora bien, en este aspecto, lo contrario a este tipo de olvido es el silencio, existiendo silencios impuestos por temor a la represión de diversos tipos de regímenes de corte dictatorial. "Los silencios durante la España franquista, la Unión Soviética stalinista o las dictaduras latinoamericanas se quebraron con el cambio de régimen. En estos casos, sobreviven recuerdos dolorosos que "esperan el momento propicio para ser expresados"” (Pollak 1989: 5).

Los silencios adquieren relevancia cuando se indaga en situaciones traumáticas, todas las que producen en las personas el quiebre de la 'memoria habitual', que mencionábamos en páginas anteriores. Específicamente, en situaciones de violencia de Estado, son fundamentales los estudios realizados sobre el Holocausto, y los sobrevivientes de la Shoah. Michael Pollak ha investigado las experiencias humanas frente a situaciones límite, que tienen como resultado identidades quebradas, fragmentadas, heridas, transformando las miradas y posibilidades de comprensión de fenómenos desgarradores (Pollak 2006). Aquí se observa también la decisión de guardar silencio, de no querer narrar ni transmitir nada, de esconder, almacenar los vestigios y rastros en zonas recónditas del olvido, para cuidar a los otros, como una forma de no querer transmitir sufrimientos. Esta es una de las características que observamos al analizar los testimonios publicados de sobrevivientes en comisiones de verdad en América Latina. No obstante "hay otra lógica en el silencio. Para relatar sufrimientos, es necesario encontrar el otro lado la voluntad de escuchar" (Jelin 2002: 31).

Un cuarto tipo de olvido es el olvido liberador, que libera de la carga del pasado para así poder mirar al futuro. Siguiendo a Ricoeur, Jelin explicita que, "es el olvido 'necesario' en la vida individual. Para las comunidades y grupos, el origen de este planteamiento está en Nietzsche, al condenar la fiebre histórica y al reclamar un olvido que permita vivir, que permita ver las cosas sin la carga pesada de la historia" (Jelin 2002: 32). En este nivel del análisis, nos encontramos con el problema de los abusos de la memoria que se pueden presentar al mismo tiempo que los olvidos. Ricoeur sugiere que estas cuestiones se deben impedir a través adecuadas políticas de gestión del pasado. Problemática que está relacionada con lo expuesto por Andreas Huyssen y que se refiere a la fiebre memorialista, la que, según su análisis, "sirvió para inventar nacionales en Europa, para legitimar Estados-nación imperiales y para brindar cohesión cultural a las sociedades en pleno conflicto tras la revolución industrial y la expansión colonial" (Huyssen 2002). 
Usos y tipologías de memorias

Las investigaciones en torno a los usos y alcances del concepto de memoria, han sido abundantes, encontrándose entre las fundacionales, las realizadas por Maurice Halbwachs ${ }^{5}$, discípulo de Émile Durkheim, que muere en uno de los tantos campos de concentración de la primera mitad del pasado siglo. Halbwachs "funda con Les cadres sociaux de la mémoire, (...) la sociología de la memoria" (Carreras 2005: 18). En este estudio elabora una diferenciación entre la memoria individual y memoria colectiva, entendiendo a ésta última como una acción de reconstrucción que realiza el conjunto humano con las motivaciones afectivas y racionales que el grupo comparte en el presente. Desde esta perspectiva, la función de la memoria es que "no revive el pasado, sino que lo reconstruye" (Halbwachs 2004a: 203), entendiéndola como “(...) una corriente continua de pensamiento, de una continuidad tal que no tiene nada de artificial, porque ella no retiene nada del pasado que no esté viviente o sea capaz de vivir en la conciencia del grupo que la mantiene" (Halbwachs 2004b: 54). Explica que nuestros recuerdos tienen cierta sintonía con la historia de la que somos parte y que además están relacionados con recuerdos comunes adscritos al grupo, por tanto, tienen una relación de alteridad. Siguiendo a Marie-Claire, Lavabre, observa que el análisis de Halbwachs se puede articular en tres tesis.

[primero] El pasado no se conserva, sino que es reconstruido a partir del presente. [Segundo]Después, dado que el individuo aislado es una ficción, la memoria del pasado no es posible sino en razón de los marcos sociales de la memoria, o a la inversa, la memoria individual no es real sino en tanto que partícipe de la memoria colectiva. [Tercero]Por último, existe una función social de la memoria. El pasado, mitificado, es utilizado para justificar las presentaciones sociales del presente. En otros términos, la memoria es efecto del presente, como lo es del pasado." (Lavabre 2006; 46).

Las condiciones mediante las cuales recordamos se inscriben en fronteras comunes "que condicionan la memoria de los individuos, a través de procesos de intercomunicación, de dominio y a través del mismo lenguaje" (Carreras 2005: 19). O, como señalaba, Marc Bloch, "no olvidar que cuando se habla de memoria colectiva se está hablando, en definitiva, de hechos de comunicación entre individuos" (Lavabre 2006: 47). Es interesante reflexionar sobre los procesos de socialización de los recuerdos, por ejemplo, en la educación, donde se intenta re-presentar cierto pasado y silenciar otros. Halbwachs señala que el recuerdo puede ser caracterizado como un proceso de reconstrucción imaginativa, en el que se integran imágenes específicas formuladas en el presente, en particulares contextos identificados con el

5 Halbwachs, M., en 1944 fue detenido junto a su hijo por la Gestapo, para luego ser enviado a Buchenwald donde murió en 1945. 
pasado. "Las imágenes recordadas no son evocaciones de un pasado real sino re-presentaciones de él. Y la forma que esta representación adquiere, depende del contexto social que la re-significa" (Mudrovcic 2005: 116). Para Halbwachs, el recuerdo no se conserva, se reconstruye a partir del presente, insistiendo en que:

Las exigencias presentes de la sociedad reglan la posibilidad de acordarse o no de un acontecimiento, al mismo tiempo que imponen la deformación del pasado. La memoria se inscribe en una materialidad, un espacio y lugares específicos donde se reconocen los grupos activos en la sociedad. Desde este punto de vista, la memoria es necesariamente plural, multiforme y se inscribe en la multiplicidad de tiempos sociales y espacios diferenciados de los cuales se apropian los grupos. (Lavabre 2006: 9).

Tema no menos complejo, por cuanto advertimos un entramado epistémico puesto que se considera al recuerdo como huella o vestigio del pasado. En esta línea Peter Burke señala que "Fue Marc Bloch quién señaló los peligros de tomar términos de la psicología individual y simplemente añadirles el adjetivo "colectivo" (...). Pese a esta crítica, Bloch adoptó la expresión mèmorie collective y analizó las costumbres campesinas en estos términos interdisciplinares, observando, por ejemplo, la importancia de los abuelos en la transmisión de las tradiciones (...)" (Burke 2006: 67). Marie-Clarie Lavabre, analiza el planteamiento de Halbwachs señalando que "el finalismo y antropoformismo de sus fórmulas, lo invitaba a reflexionar acerca de los mecanismos concretos que autorizan la memoria colectiva, las modalidades necesarias para la transmisión del pasado, la relación de los individuos con el grupo y las consecuencias «prácticas y políticas» de la existencia de la memoria colectiva” (Lavabre 2006: 10).

La investigación fundacional de Pierre Nora, al que hacen referencia gran parte de los trabajos sobre la memoria histórica, sigue la huella de Maurice Halbwachs, ya que examina la relación entre la memoria y su marco espacial, presentando desde esta perspectiva una visión de la construcción histórica, específicamente centrado en la historia de Francia. Sin embargo, antes de la publicación de Les lieux de mémoire, Pierre Nora elaboró en un artículo de la colección La Nueva Historia, dirigida por Jacques Le Goff, una excelente definición del concepto de memoria, artículo que según Marie-Claire Lavabre abre el "momento-memoria" (Lavabre 2006: 39), ya que anuncia el proyecto posterior, de 'los lugares de memoria', no sin antes exponer las complejidades del propio término: "Hablar de memoria colectiva plantea el mismo tipo de dificultades y pone en juego similares problemas que hace treinta años la 
palabra 'mentalidades'. La expresión es por demás vaga y ambigua, pero su utilización estratégica puede ser fecunda para la renovación historiográfica" (Lavabre 2006: 40).

En ese pionero texto, Nora elaboró una conceptualización preliminar sobre estos temas, argumentando que: "En una primera aproximación, la memoria colectiva es el recuerdo o conjunto de recuerdos, conscientes o no, de una experiencia vivida y/o mitificada por una colectividad viviente, de cuya identidad el pasado forma parte integrante" (Lavabre 2006: 40). Enfatizó la necesidad de tomar a la memoria como objetivo de estudio de la historia, esto es que, "el análisis de las memorias colectivas puede y debe transformarse en la punta de lanza de una historia que se defina como contemporánea" (Lavabre 2006: 40). Siguiendo esta argumentación, Marie- Claire Lavabre señala que "este 'divorcio liberador y decisivo' entre historia y memoria permite definir la memoria como algo diferente de la historia, y la historia misma como algo diferente de la memoria" (Lavabre 2006: 40). Y esta es una de las grandes cuestiones que más tarde generará innumerables debates y reflexiones, entre las más profusas se encuentran las de Josefina Cuesta y Julio Aróstegui.

La contribución al estudio de la memoria histórica de Halbwachs y Nora, "ponen de relieve que la memoria individual no es sino una instancia social de recordar" (Mudrovcic 2005: 115). Insistiendo Nora en que la memoria colectiva es "lo que queda del pasado en lo vivido de los grupos, o eso que los grupos hacen del pasado" (Le Goff 1991: 178), enfatiza además que "la memoria es un problema histórico reciente, nuestro problema" (Cuesta 1993: 41). En ello también coinciden Aróstegui y Cuesta, manifestando no sólo la relación dinámica entre historia y memoria, sino también las dificultades que comportan estos temas de los cuales muchas veces somos coetáneos. Por ello destacamos la utilidad del concepto para el análisis histórico, ya que permite examinar las múltiples formas en que el pasado se registra y recuerda. Y que en palabras de Nora podemos centrar nuestras preocupaciones, "no en el recuerdo, sino en la economía general y la administración del pasado en el presente" (Lavabre 2006: 41). En este aspecto Lavabre explica que lo que la memoria histórica designa no es lo vivido, ni la experiencia, ni los recuerdos, ya que esto puede ser lo propio de la memoria colectiva, sino más bien, el proceso por el cual los conflictos y los intereses del presente operan sobre la historia. Plantea además que se denominará memoria histórica a los usos del pasado y de la historia, tal como se la apropian grupos sociales, partidos, iglesias, naciones o Estados.

$6 \mathrm{La}$ autora hace referencia al texto de Nora, P. "Mèmorie collective", en Le Goff, J. (dir.) (1978). La nouvelle histoire. Les encyclopédies du savoir moderne, Paris, RETZ. 
Estas preocupaciones se suman a la de otros analistas, quienes insisten en elaborar mayores precisiones cuando se aborda como un todo la 'memoria colectiva', puesto que, de un lado, reflejan las complejas equivalencias entre memoria individual y colectiva, y de otro, resulta innegable la influencia que ejerce sobre las personas, la sociedad y cultura a la que pertenecen. Desde la filosofía, Ricoeur, propuso encontrar un lugar común entre memoria individual y colectiva, argumentando que los sitios de proximidad podían emanar de otras veredas vinculadas sobre todo a qué se recuerda, cómo se recuerda y quién o quiénes recuerdan. Argumenta que la memoria personal se caracteriza por tres rasgos, el primero a que es radicalmente singular, el segundo está relacionado con el vínculo original de la conciencia con el pasado, el que reside en la memoria y, por último, a que "se encuentra vinculada a la sensación de orientarse a lo largo del tiempo, del pasado al futuro" (Ricoeur 1999: 17). Siguiendo esta línea de reflexión, seríamos el reflejo de nuestro pasado, en que el presente es la manifestación de aquello que ha sucedido. En este aspecto, es importante lo planteado por Koselleck, sobre la 'conciencia histórica', a la que atribuye la imagen de huellas sedimentadas, en las que se instalan nuestros deseos, miedos y proyectos. En consecuencia "sólo existiría el espacio de experiencia cuando éste se opone a un horizonte de espera” (Ricoeur 1999: 22). Desde esta perspectiva, lo que entendemos por 'tiempo histórico' es aquel "intercambio entre el espacio de experiencia y el horizonte de espera que se lleve a cabo en el presente vivo de una cultura" (Ricoeur 1999: 22).

Josefina Cuesta señala que las diferentes tipologías de memoria "nos ponen en la pista de la existencia de una multiplicidad de memorias en una sociedad dada (...). Concentración de memorias que plantea desafíos metodológicos, puesto que “La memoria se puebla de 'estructuras interactivas' a las que se denomina 'esquemas'. Estos esquemas se abstraen de la experiencia de forma que constituyen modelos del mundo exterior, que sirven a su vez 'para procesar' toda nueva información. La memoria no es, pues, una reproducción del mundo exterior, sino un aparato para reinterpretarlo" (Cuesta 1993: 45). En este sentido, Julio Aróstegui argumenta que la memoria no se limita a la posibilidad de recordar y de traer 'al presente el pasado', sino que también tiene la capacidad de seleccionar. Problemática que no es ajena a la de las relaciones entre la memoria y el poder, como lo señala Josefina Cuesta. Asimismo, Paul Ricoeur comienza su estudio sobre la fenomenología de la memoria con dos preguntas “¿de qué hay recuerdo?, ¿de quién es la memoria” (Ricoeur 1999: 19). Interrogantes que ingresan a lo que Elizabeth Jelin denomina como 'disputas por la memoria'. Pero aún más, porque también tiene relación con los 
usos de las memorias, los silencios y olvidos. "El silencio y el olvido tienen 'usos', que ejercen un papel en el mantenimiento de las vivencias y ocupan un lugar de relevante importancia en la reproducción social y en la plasmación del discurso histórico" (Aróstegui 2004: 159). En esta misma línea, Nora propone estudiar la memoria como "un lugar de encrucijada entre las políticas públicas, cultura y tradición que consolidan un espacio de y para la memoria y para la transmisión del recuerdo" (Cuesta 1998: 209).

Como lo han planteado la mayoría de los autores citados 'vivimos el tiempo de la memoria', junto al 'tiempo del testigo', que junto a las interrogantes ¿por qué y para qué recordar?, emergen como la matriz para analizar las últimas décadas del siglo XX, donde la impronta de los Nunca Más, es uno de los anhelos en que coinciden las sociedades del siglo XXI. "Uno de los fenómenos culturales y políticos más sorprendentes de los últimos años es el surgimiento de la memoria como una preocupación central de la cultura y de la política de las sociedades occidentales” (Aróstegui 2004: 161). Julio Aróstegui, explica estas preocupaciones, referidas a la memoria histórica, las que, de acuerdo a su análisis, se vienen masificando sobre todo a partir de 1990, y que, desde diversos escenarios tanto del quehacer político como cultural, se observa un reclamo de grupos sociales por preservar la memoria, en especial aquello que se refiere a "la memoria del dolor, de las guerras, de las injusticias, la represión y los genocidios" (Aróstegui 2004: 161). Estas inquietudes se extienden también hacia la forma en cómo se aborda la problemática del estudio de la memoria, donde a su juicio se observa por un lado una cierta saturación de memoria, y por otro, la necesidad de convertirla en un objeto historiográfico, cuya característica también es la de ser definidora de pautas culturales (Aróstegui 2004: 161).

Respecto a la clasificación de los tipos de memoria, Josefina Cuesta explica que "La clasificación inicial de M. Halbwachs ha sido completada, en muchos casos, con experiencias posteriores de historiadores como R. Frank, M.C. Lavabre, G. Namer o H. Rousso, entre otros” (Aróstegui 2004: 42). La historiadora señala que son mucho más operativo los conceptos de "memoria individual, memoria colectiva, memoria oficial, memoria pública, memoria popular, memoria culta, y memoria social o difusa. Algunas obras introducirán algún otro como memoria común, memoria manipulada, borrada o recobrada" (Aróstegui 2004: 42). Examina los diferentes tipos de memoria y propone tres grandes diferenciaciones para el estudio de la memoria. La primera es la 'memoria social', que se puede entender como "el conjunto de nociones o saber vago que reposa en el entorno y en el medio social. Como la 
individual, se caracteriza por su escasa definición y conceptuación" (Aróstegui 2004: 43) que, según estas directrices, "se sitúa fuera de los grupos y de sus respectivas memorias y, aunque actúa como marco, origen y consecuencias de éstas, no propicia ninguna homogeneidad de grupo" (Aróstegui 2004: 43). La segunda es la 'memoria popular', que, de acuerdo a su análisis, tiene como elemento común con la memoria social su carácter interindividual, por lo tanto, no pertenece a un grupo establecido, y en consecuencia no es 'colectiva'. Además, señala que este tipo de memoria se distingue "por su carácter más concreto y definido, y que, a través de ella, se transmitirían y organizarían los ritmos de trabajo, las costumbres y tradiciones, y ciertos hábitos sociales" (Aróstegui 2004: 44). En contraposición a este tipo de memoria está la 'memoria culta', también denominada como 'memoria especializada', se trata de aquella memoria que es "recogida y transmitida por los historiadores, cuya acción sería, de ordinario, desmitificadora y deletérea. Aunque no por ello deja de ejercer su influjo en la memoria colectiva, en la que provoca una cierta adaptación" (Cuesta 1998: 44). Le sigue una 'memoria oficial', que se identifica como "de las instancias del Estado -o de organismos oficiales- [que] intenta la glorificación, mitificación $\mathrm{o}$, en otros casos, la ocultación para elaborar, propagar y mantener una identidad y una memoria "nacionales"' (Cuesta 1998: 44). Las tipologías de memorias que identifica Josefina Cuesta dan cuenta de su complejidad, pero también de los elementos comunes que tienen, así como de su finitud debido al carácter selectivo. "Se formula en el lenguaje y a través de los esquemas mentales de cada época y grupo, (...). Es selectiva en la medida en que nunca es total ni omnicomprensiva, y aquí radica su delimitación respecto a los hechos y su importancia" (Cuesta 1998: 45) ${ }^{7}$. Otra característica de la memoria es que es acumulativa, puesto que "cada experiencia humana se organiza en el eje de temporalidad y de la sucesión, lo que permite hablar de sedimentación y de una multiplicidad de memorias en reestructuración constante" (Cuesta 1998: 45). Afirmación que descansa en los análisis propuestos por Koselleck, referidos al horizonte de espera. Observamos, por tanto, que la diversidad que caracteriza a las memorias es compleja, hecho del que dan cuenta muchos de los autores ya citados, por cuanto "plantea notables problemas epistemológicos y metodológicos a la hora del análisis de la memoria y de la estructuración, articulación y jerarquización de todas ellas, en un momento dado. Problemática que no es ajena a las de las relaciones entre la memoria y el poder" (Cuesta 1998: 45).

Lo expuesto da cuenta de la complejidad que tiene el estudio de las memorias. Aróstegui señala que según la función y el uso de la memoria se puede considerar como "factor de concienciación histórico-

7 La historiadora indica que, "una historia de la memoria lleva aparejada, inseparablemente unida, una historia del olvido". 
social y cultural, [ya que] que existen decisivas diferencias entre las memorias sociales justamente en relación con la experiencia" (Cuesta 1998: 46), elaborando también una diferenciación sobre los tipos de memoria:

Existe una memoria directa, llamada también, a veces, espontánea, frente a otra adquirida o transmitida, o, lo que es lo mismo, una memoria ligada a la experiencia vital, propia y directa, del individuo o el grupo, la memoria viva, y otra que es producto de la transmisión de otras memorias, de la memoria de los predecesores, la memoria heredada. Hay, en fin, una memoria institucional (...), cuyos contenidos son clave para la práctica $y$ la reproducción social. (Cuesta 1998: 46).

Estos cruces de memorias resultan fundamentales para el análisis de la memoria histórica. Las formas de dividir los diferentes tipos de memorias, dan cuenta de la dificultad metodológica que mencionábamos antes, pero también exponen un interés por objetivarla y de esta forma historizarla. Josefina Cuesta, explica que una de las características de la memoria como concepto es su 'plasticidad', reconoce la diversidad que ofrece en lo que se ha llamado "géneros de memorias" (Cuesta 1998: 210), observando que

La sociología de la memoria ha alcanzado un notable conocimiento de la memoria familiar mediante la aplicación de las más diversas variables de análisis: los tipos de memorias y sus lógicas organizativas, la finalidad que sostienen y la jerarquización que se origina entre ellas en el interior de la propia familia, su extensión temporal en el pasado, sus actitudes respecto a éste y los soportes en los que se apoyan, más las diferencias de género y edad, la diversidad del medio social y de actividad profesional de sus miembros. (Cuesta 1998: 210).

Explica, además, que la historiografía ha centrado su análisis de la memoria histórica en "tres grandes conjuntos: clase, pueblo y nación" (Cuesta 1998: 210), insistiendo en lo inabordable que resulta abarcar en un todo la memoria de una sociedad. Por ello tal vez la pertinencia metodológica de situar en compartimentos de 'libre tránsito' las diferentes memorias con el objetivo de que sean fácilmente aplicables para analizar los procesos históricos. La historiadora argumenta que tanto la expansión de las fuentes como la emergencia de identidades antes ignoradas, ha permitido la irrupción de nuevas preguntas y enfoques que dotan de mayores posibilidades el estudio de las memorias.

La vigencia de los planteamientos teóricos y metodológicos de los autores analizados en este texto, plantean la necesidad de reflexionar sobre los elementos nodales que dotan de contenido a la historia del 
tiempo presente, donde las memorias tienen un rol clave dentro del análisis histórico, cuestión que permite pensar y analizar las presencias y sentidos del pasado. Jelin señala tres ejes fundamentales: "Primero, entender las memorias como procesos subjetivos, anclados en experiencias y en marcas simbólicas y materiales. Segundo, reconocer, a las memorias como objeto de disputas, conflictos y luchas, lo cual apunta a prestar atención al rol activo y productor de sentido de los participantes en esas luchas, enmarcados en relaciones de poder. Tercero, "historizar" las memorias, o sea, reconocer que existen cambios históricos en el sentido del pasado, así como en el lugar asignado a las memorias en diferentes sociedades, climas culturales, espacio de luchas políticas e ideológicas” (Jelin 2002: 2).

En la publicación de la colección denominada Memorias de la Represión ${ }^{8}$, el primer volumen titulado Los trabajos de la memoria, explora los alcances de los usos de las memorias. Elizabeth Jelin, su autora explica que "referirse entonces a que la memoria implica un 'trabajo' que es incorporarla al quehacer que genera y transforma el mundo social" (Jelin 2002: 14). La contribución de este texto es fundamental ya que analiza las complejidades de la memoria dentro de una situación traumática, incorporando tiempo y espacio en clave latinoamericana, en un contexto de violencia política ocurrida durante las dictaduras militares. Incorpora los análisis teóricos venidos de Europa, pero analizando América Latina. Expone una tipología de memorias siguiendo a teóricos como Norbert Elias y Marcel Mauss. "La vida cotidiana está constituida fundamentalmente por rutinas, comportamientos habituales, no reflexivos, aprendidos y repetidos. El pasado del aprendizaje y el presente de la memoria se convierten en hábito y tradición. No hay nada 'memorable' en el ejercicio cotidiano de estas memorias" (Jelin 2002: 26). A este tipo de comportamientos aprendidos los denomina 'memoria habitual'. Argumenta que las rupturas de esas rutinas esperadas involucran al sujeto de manera diferente, que compiten afectos y sentimientos que pueden llevar no sólo a una reflexión sino también a la búsqueda de sentido.

(...) es este compromiso afectivo lo que transforma esos momentos y los hace «memorables». La memoria es otra, se transforma. El acontecimiento o el momento, cobra entonces una vigencia asociada a emociones y afectos, que i mpulsan la búsqueda de sentido. El acontecimiento rememorado o «memorable» será expresado en forma de narrativa convirtiéndose en la manera en que el sujeto construye

8 "La colección de libros Memorias de la Represión es el resultado de un programa desarrollado por el Panel Regional de América Latina (RAP) del Social Science Research Council, con el propósito de promover la investigación y la formación de investigadores sobre las memorias de la represión política en el Cono Sur. Bajo la dirección de Elizabeth Jelin y Carlos Iván Degregori, y con fondos proporcionados por las fundaciones Ford, Rockefeller y Hewlett, el programa apoyó a cerca de 60 investigadores jóvenes de Argentina, Brasil, Chile, Paraguay, Perú, Uruguay y los Estados Unidos. El programa fue diseñado para encarar tres cuestiones diferentes, aunque relacionadas entre sí”. Recuperado de https://www.sigloxxieditores.com/libro/los-trabajos-de-la-memoria_16595/ 
sentido del pasado, una memoria que se expresa en un relato comunicable (...). (Jelin 2002: 27).

Esta es una 'memoria narrativa', y para Jelin se observan dos elementos centrales, primero, puesto que el pasado cobra sentido en su conexión con el presente en el acto de rememorar, pero también en el acto de olvidar. Segundo, en que la pregunta por el pasado es un proceso subjetivo. Por tanto "el acto de rememorar presupone tener una experiencia pasada que se activa en el presente, por un deseo o sufrimiento, unidos a veces a la intención de comunicarla" (Jelin 2002: 27). Señala que son estas memorias las que le interesan por cuanto dentro de ellas "están las que pueden encontrar o construir los sentidos del pasado y las «heridas de la memoria» más que las «memorias heridas», que tantas dificultades tienen en constituir su sentido y armar su narrativa" (Jelin 2002: 29).

En este análisis coincide Steve Stern, que investiga la historia de América Latina, cuyas reflexiones las ha centrado en el análisis de lo que denomina 'memoria emblemática'. En un profuso estudio para el caso de Chile y la dictadura cívico-militar (1973-1990) elabora una conceptualización y teorización sobre la memoria emblemática, indicando que se debe conceptualizar cuáles son sus 'nudos', entendiendo por éstos a los grupos humanos, hechos, fechas y sitios o restos físicos, que convocan diferentes tipos de memorias y también de olvidos. “(...) la historia de la memoria y el olvido colectivo es un proceso de deseo y de lucha para construir las memorias emblemáticas, culturalmente y políticamente influyentes y hasta hegemónicas. Es una lucha para crear ciertos tipos de puentes entre la experiencia y el recuerdo personal y suelto, por un lado, y la experiencia y el recuerdo emblemático colectivamente significativo por otro lado" (Stern: 2000; 13). Explica que la 'memoria emblemática', no es sólo algo concreto y sustantivo de un solo contenido; más bien es una especie de marco, una forma de organizar las memorias y sus sentidos. Para su explicación toma como ejemplo el golpe de Estado en Chile del 11 de septiembre de 1973, que como acontecimiento marca la historia de este país, analiza las memorias que se generan frente a este hecho. Subraya que la memoria emblemática es, por tanto, un marco y no un contenido concreto, que también crea una forma de organizar el sentido de los recuerdos, de la contra-memoria y el debate.

Da un sentido interpretativo y un criterio de selección a las memorias personales, vividas y medio sueltas, pero no es una sola memoria, homogénea y sustantiva. Los contenidos especificos y los matices no son idénticos ni de una persona a otra, ni de un momento histórico a otro. La memoria emblemática es una gran carpa en que hay un "show" que va incorporando $y$ dando sentido y organizando varias memorias, articulándolas al sentido mayor. Este sentido mayor va definiendo cuáles 
son las memorias sueltas que hay que recordar, dándoles la bienvenida a la carpa y su show, y cuáles son las cosas en cuyo caso mejor es olvidarlas o empujarlas hacia los márgenes (Stern 2000: 14).

En el estudio citado examinó durante varios años "las principales memorias emblemáticas que han ido construyendo los chilenos a partir de 1973, cuando trataron de definir cómo recordar el significado del Once y cómo recordar la dimensión más controvertida del gobierno militar: la violencia política masiva que se ejercía desde el Estado" (Stern 2000: 15).

Identificó cuatro memorias emblemáticas principales sobre los temas del golpe de Estado en Chile y la violación de derechos humanos: La memoria como salvación, como ruptura lacerante y no resuelta, como prueba de la consecuencia ética y democrática y, por último, la memoria como el olvido o caja cerrada, que a juicio del Stern, se trataría "de un olvido lleno y cargado de memoria. [Y que] define lo útil del olvido y define las cosas que más vale olvidar. Define, también, los peligros y los conflictos insuperables que hay que recordar" (Stern: 2000; 17). Al mismo tiempo, indica que, al tratar estos temas referidos a las memorias emblemáticas, es preciso tener ciertas precauciones con el fin de evitar caer en algunos errores de orden conceptual, insistiendo en que los procedimientos a través de los cuáles se fraguan las memorias son complejos.

En la misma línea Pedro Milos analiza también para el caso de Chile, la memoria y sus significados, entendiéndola como práctica social que elabora recuerdos a partir de vivencias individuales o colectivas. Examina las diversas memorias que rodean un acontecimiento capital. Advierte, como lo expone también Elizabeth Jelin, que existen memorias en conflicto, que coexisten con políticas que inducen el olvido. Milos elabora una sistematización conceptual sobre la memoria, donde identifica aquellas que ubican a la memoria como

(...) la expresión de realidades sociales y culturales determinadas, hasta aquellas que la conciben como representaciones culturales de orden simbólico, se trata en general de conceptualizaciones que ponen el acento en la memoria como significación. Significaciones que son muy diversas y que comprometen distintas dimensiones: lo individual y lo colectivo, lo objetivo y lo subjetivo, lo pasado y lo presente, lo explícito y lo implícito. (Milos 2000; 39).

Lo interesante es constatar que la gran mayoría de las especificaciones sobre los diversos tipos de memoria, vertebran de una u otra manera los postulados propuestos por Maurice Halbwachs sobre la memoria, puesto que "enfatiza en los aspectos sociales de su producción y, por tanto, de su recuperación y de su interpretación” (Milos 2000: 48). Reconoce además el peso de la realidad social en la gestación 
de la memoria, hecho que permite la existencia de múltiples memorias, cuestión en la que coinciden gran parte de los autores consultados.

Enzo Traverso subraya que las sociedades recuerdan de manera intensa o de manera suave, indica que "hay memorias fuertes y memorias débiles. Donde el Holocausto, pasó a ser de una memoria débil a una memoria fuerte" (Figueroa, Iñigo 2010: 20). Los historiadores Carlos Figueroa y Nicolás Iñigo, señalan en el caso de las violaciones de derechos humanos en el Cono Sur de América, que "son parte de una 'memoria fuerte'. Mientras que el más grande genocidio en el continente americano, el que se observó en Guatemala, es parte de una 'memoria débil'" (Figueroa, Iñigo 2010: 20)9 . Argumentan que esto se debe a que ese tipo de memoria traumática tiene más presencia en la sociedad civil de Argentina, Chile y Uruguay, que en la de la sociedad guatemalteca. Estos autores, agregan además que "si fuera cierto, que la Historia Reciente es hija del dolor, y si esto se expresara en que, en el Cono Sur, sean las dictaduras militares y terroristas 'el punto de ruptura que ha promovido los estudios del pasado cercano', la ausencia de esta memoria o su expresión como 'memoria débil', explicaría el tema de la historia reciente en Guatemala" (Figueroa, Iñigo 2010: 20-21). En este sentido, señalan que la 'memoria de la infamia'como ellos la denominan- puede observar omisiones debido a la autocensura que la expone como una 'memoria mutilada'. Identifican la necesidad de una 'Historia Reciente', que rescate del olvido la 'memoria de la infamia', sino también las otras memorias, ya que son fuente para el estudio de estas sociedades.

\section{Reflexiones posibles}

Las disputas sobre el pasado reciente en sociedades que han experimentado la violencia política es un tema pendiente, en el que confluyen las voces de las víctimas que claman justicia, y muy a menudo el silencio de los que antes mantuvieran el poder. Entre unos y otros existe un abismo inconmensurable, la violencia de estado que se aplicó en gran parte de Latinoamérica, los miles de víctimas, detenidos, torturados, ejecutados políticos y desaparecidos, es el panorama con el que se recibe el nuevo siglo, donde Chile no es una excepción. Tema aparte resultan los pactos y consensos a los cuales se accedió y la forma en que se fueron aceptando los elementos esgrimidos en constituciones creadas durante las

9 Ambos historiadores argumentan que, "Pese a las 45 mil desapariciones forzadas y 150 mil ejecuciones extrajudiciales que se observaron en dicho país entre 1960 y 1996 (ODHA, 1998; CEH, 1999), no es el caso guatemalteco el que surge como ejemplo de dictaduras militares y terroristas cuando se habla del tema en ámbitos académicos y mediáticos. Tampoco es Ríos Montt, sino que son Pinochet y Videla los paradigmas más mencionados en lo que se refiere a dictadores genocidas." 
dictaduras; para el caso de Chile, la Constitución de 1980, que estableció el ideario del dictador y la forma cómo se transitaría a una democracia tutelada.

Es aquí donde tanto las palabras como las preguntas frente al pasado traumático toman consistencia. Desde la historia del tiempo presente, nos interrogamos sobre un pasado, como señala Julio Aróstegui, "del que se es contemporáneo y que vive en los recuerdos de la gente, y que se pretende abordarlo como historiador pese a su proximidad." Ese es el desafío mayor. Para ello hemos tomado como eje de análisis, las relaciones entre historia y memoria. Fundamentales son los trabajos realizados desde la sociología por Maurice Halbwachs, y los múltiples debates en torno a su concepto de memoria colectiva. Desde la historia, la emblemática obra de Pierre Nora, sobre los lugares de memoria resulta clave. En la metáfora elaborada por el historiador, caben gran cantidad de elementos, tales como fechas, lugares, textos, sitios, instituciones, todos los cuales respaldan una memoria mayor, entendida para unos como nacional y para otros como pertenecientes a grupos que han experimentado un pasado común.

En las investigaciones realizadas en América Latina sus contribuciones han sido fundamentales, ampliando la base conceptual, e incorporando en sus análisis las disputas por las memorias y los sentidos sociales del pasado reciente, identificándolas en territorios determinados que, junto a las fechas de conmemoración, monumentos, y archivos de la represión, otorgan múltiples posibilidades investigativas. Son estas huellas las se intentan seguir en este tipo de investigaciones, en este aspecto los trabajos de Elizabeth Jelin, Elizabeth Lira, y Anne Pérotin-Dumon, resultan fundamentales en el estudio de estos temas.

La re-escritura de la historia es una tarea pendiente, sobre todo para las nuevas generaciones de historiadoras e historiadores. Debemos ingresar a los archivos, indagar en aquellas fisuras, en las fracturas que se tiñen de olvido, reflexionando sobre las formas en que se instalan en las actuales democracias. Indagar parafraseando a Benedetti en aquel olvido que está lleno de memoria.

\section{Referencias bibliográficas}

Anderson B. (2006), Comunidades imaginadas. Madrid, España, F.C. E. 
Arendt H. (1969), Sobre la Violencia. Madrid, Alianza Editorial.

Aróstegui J. (1998). “Tiempo contemporáneo y tiempo presente. Una reconsideración necesaria”. En Díaz Barrado, M. (coord.), Historia del tiempo presente. Teoría y Metodología. Seminario de Historia del Tiempo Presente. Extremadura, España: Instituto de Ciencias de la Educación, Universidad de Extremadura.

(2004) La historia vivida. Madrid, Marcial Pons.

Barahona A., Aguilar P., González C. (ed.), (2002). Las políticas hacia el pasado. Juicios, depuraciones, perdón y olvido en las nuevas democracias. Madrid, Istmo.

Bédarida F. (1998), "Definición, método y práctica de la Historia del tiempo presente”. En Cuadernos de Historia Contemporánea, N²0. Madrid, UCM.

Bloch, M. (2002). La extraña derrota. Barcelona, Crítica.

(1996). Apología para la historia o el oficio del historiador. Madrid, F. C. E.

Bourdieu P. (1988), La distinción criterios y bases sociales del gusto. Madrid, Taurus.

Burke P. (2006), Formas de Historia Cultural. Madrid, Alianza Editorial.

Cabrera M. A., Mc Mahon M. (coord.), La situación de la Historia: Ensayos de Historiografía. La Laguna, España: Universidad de la Laguna.

Carreras Ares J. J. (2005), “¿Por qué hablamos de memoria cuando queremos decir Historia?” en Sabio A., Forcadell C. (coord.). Las Escalas del pasado: IV Congreso de Historia Local de Aragón. Barbastro, Instituto de Estudios Altoaragonés/ UNED.

Cuesta J. (1993), Historia del presente, Madrid, Eudema Historia.

Cuesta Bustillo, J. (1998), "Historia del presente y periodismo" en Díaz Barrado M. P., Historia del Tiempo Presente. Teoría y Metodología. Extremadura, Universidad de Extremadura.

(1998), “Memoria e historia. Un estado de la cuestión". En Revista Ayer $n^{\circ} 32$.

Madrid, España; Marcial Pons. 
De Certeau M. (1999), La escritura de la Historia. México, Universidad Iberoamericana.

De Mussy L. y Yávar A. (2008), Seminario. Transiciones políticas Comparadas: España y Chile. Temas, fuentes y Metodología, Cuadernos de trabajo, Santiago, Universidad Finis Terrae-UMCE.

Farge A. (2008), Efusión y tormento. Relato de los cuerpos. Madrid, Katz.

Farge A. (2010), Lugares para la Historia. Santiago, Chile, Universidad Diego Portales.

Figueroa M. y Vicuña M. (coord.) (2008). El Chile del bicentenario, Santiago, Ediciones UDP.

Figueroa I. C., Iñigo C. N. (2010) "Reflexiones para una definición de Historia Reciente", en López M., Figueroa C. y Rajland, B. (ed.), Temas y procesos de la Historia Reciente de América Latina, Santiago, Arcis- CLACSO, 2010.

Halbwachs M. (1994), Historia del siglo XX. Barcelona, Crítica.

(1998), Sobre la historia. Barcelona, Crítica.

(2004a), Los Marcos Sociales de la Memoria. Barcelona, Anthropos.

(2004b), La Memoria Colectiva. Zaragoza, Prensas Universitarias de Zaragoza.

Huyssen A. (2002), En busca del futuro perdido: Cultura y memoria en tiempos de globalización. Madrid, F. C. E.

Iuorno G. (2010). “A propósito de la Historia reciente: ¿Es la interdisciplinaridad un desafío epistémico para la Historia y las Ciencias Sociales"? en López M. Figueroa C. y Rajland B. (ed.). Temas y procesos de la Historia Reciente de América Latina. Santiago, Chile, Arcis-CLACSO.

Jelin E. (2002), Los trabajos de la memoria, Colección Memorias de Represión, Madrid, Siglo XXI Editores.

(2002) (comp.), Las conmemoraciones: Las disputas en las fechas "in-felices", Madrid, Siglo XXI Editores. 
Jelin E. y Da Silva L. (comps.) (2002), Los archivos de la Represión: Documentos, memoria y verdad. Madrid Siglo XXI Editores.

Jelin E. y Langland V. (comps.) (2003), Monumentos, memoriales y marcas territoriales. Madrid, Siglo XXI Editores.

Jelin E. y Longoni A. (comps.) (2005), Escrituras, Imágenes y escenarios ante la represión. Madrid, Siglo XXI Editores.

Lavabre M.C. (2006), "Sociología de la memoria y acontecimientos traumáticos", en Aróstegui J., Godicheau F. (eds.). Guerra Civil. Mito y memoria. Madrid, Marcial Pons, Casa de Velásquez.

(2007), "Maurice Halbwachs y la sociología de la memoria", en Pérotin-Dumon, A. (dir.), Historizar el pasado vivo en América Latina. Santiago, Chile; UAH. Recuperado de http://etica.uahurtado.cl/historizarelpasadovivo/es contenido.php. 2007

Le Goff J. (1991), El orden de la memoria. El tiempo como imaginario. Barcelona, Paidós.

Lewis G. J. (2004), El paisaje de la Historia: cómo los historiadores representan el pasado. Barcelona, Anagrama.

Mauss M. (1991), Sociología y antropología. Madrid, Tecnos.

Milos P. (2000), “La memoria y sus significados”. en Garcés M. et. al. (comps.) Memoria para un nuevo siglo. Chile, miradas a la segunda mitad del siglo XX. Santiago, Chile, LOM.

Mudrovcic M. I. (1998-2000), "Algunas consideraciones epistemológicas para una "Historia del Presente", en Hispania Nova, Revista de Historia Contemporánea № 1. Madrid. Recuperado de http:/hispanianova.rediris.es/general/articulo/013/art013.htm

historia. Madrid, AKAL.

(2005), Historia, narración y memoria: Los debates actuales en filosofía de la

Nora P. (1992), "La aventura de Les lieux de mémoire", en J. Cuesta (Ed.) Memoria e Historia, Ayer No 32. Madrid, Marcial Pons.

Pérotin-Dumon A. (2007), "Liminar. Verdad y memoria: escribir la historia de nuestro tiempo", en Pérotin-Dumon, A. (dir.), Historizar el pasado vivo en América Latina. Santiago, Chile: UAH. Recuperado de http://etica.uahurtado.cl/historizarelpasadovivo/es_contenido.php 
Pollak M. (1989), "Memória, esquecimiento, silêncio", en Estudios históricos vol. 2, № 3, Río de Janeiro.

situaciones

(2006), Memoria, olvido, silencio. La producción social de identidades frente a

limite. La Plata, Ediciones al Margen.

Ricoeur P. (1999), La lectura del tiempo pasado: Memoria y olvido. Madrid, Arrecife-UAM.

(2003). La memoria, la historia, el olvido. Madrid, Trotta.

Salazar G. (2007), "Historiografía chilena siglo XXI: transformación, responsabilidad, proyección". en De Mussy L. (Ed.). Balance Historiográfico Chileno. El orden del discurso y el giro crítico actual. Santiago, Chile, Ediciones Finis Terrae.

Semprún J. (1997), La escritura o la vida. Barcelona, España; Tusquets.

Sierra B. (2000), “¿Cómo está representada la experiencia de la memoria en psicología cognitiva de la memoria?" en Revista Anthropos, N $^{\circ} 189-190$, Barcelona, Anthropos.

Spiegel G. (2002), "Memoria e Historia: Tiempo litúrgico y Tiempo histórico”, en Cabrera M. A., Mc Mahon M. (coord.). La situación de la Historia: Ensayos de Historiografía. La Laguna, Universidad de la Laguna.

Stern S. (2000), "De la memoria suelta a la memoria emblemática: hacia el recordar y el olvidar como procesos históricos (Chile, 1973-1998)", en Garcés M., et. al. (comps.), Memoria para un nuevo siglo. Chile, miradas a la segunda mitad del siglo XX. Santiago, Chile, LOM.

Todorov T. (2005), Los abusos de la memoria. Barcelona, Paidós.

Trebitsch M. (1998), "El acontecimiento, clave para el análisis del tiempo presente”, en Cuadernos de Historia Contemporánea, $\mathrm{N}^{\mathrm{0}}$ 20. Madrid, UCM.

Yerushalmi Y. H. (1998). "Reflexiones sobre el olvido", en Yerushalmi Y. (et. al.), Usos del Olvido. Buenos Aires, Nueva Visión. 